\title{
64th AALAS National Meeting
}

\section{7-31 OCTOBER 2013}

Baltimore Convention Center

Baltimore, MD

Attendees: 4,823

Exhibiting companies: 287

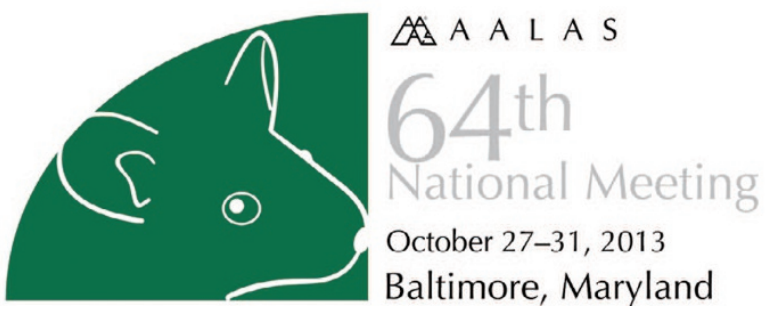

and his colleagues learned much about the physiology and ecology of a very poorly understood species. He also described some of the creative approaches that his staff has used to facilitate caring for some of the more exotic and challenging animals housed at the Aquarium. For example, one aquarist trained an electric eel to enter a net and be removed from its home tank without discharging its 500-volt shock, a benefit to both eel and handler! Similarly, 'Margaret,' the aquarium's hyacinth macaw, is trained to "go to sleep," lying still on her back while a caretaker gently swaddles her and administers a sedative. Both 'tricks' enable veterinarians to complete routine health checks quickly and safely.

On Tuesday, October 29, Wallace P. Rowe Lecturer Janice Clements described how macaques with simian immunodeficiency virus (SIV) have been used as a model for research on human immunodeficiency virus (HIV) and acquired immune deficiency syndrome (AIDS). Clements and her team have gained insights into the mechanisms of early viral infection and immune signaling in the brain from studying the SIV-infected macaques. They have also investigated the use of combined antiretroviral therapy in the macaques to suppress viral replication and eradicate reservoirs of latent virus in blood and tissues. Clements hopes that the results of these studies one day may lead to a cure for AIDS.

Meanwhile, down the hallway, Kathryn Chapman gave the Charles River Ethics and Animal Welfare Lecture on the importance of the principles of the 3Rs (replacement, refinement and reduction of animal use in research) in guiding the use of animals during drug development. Chapman brings together expert working groups, specializing in topics such as regulatory toxicology, monoclonal antibody production and acute toxicity, to support the sharing of data and experience in order to identify and promote opportunities to minimize animal use in the pharmaceutical industry.

Other meeting highlights included the introduction of Scott Mischler as the 2014 AALAS President in a gavel ceremony during the General Membership Meeting on Monday, October 28. Kim Saunders became Past-President, Cindy Buckmaster became Vice President and Laura Conour joined the 2014 AALAS officers as Vice President-Elect. 